\section{Which factors are associated with quality of life in patients with Graves' orbitopathy presenting for orbital decompression surgery?}

S Wickwar ${ }^{1,2}, \mathrm{HB}$ McBain ${ }^{1,3}$, DG Ezra ${ }^{2,4}$, SP Hirani ${ }^{1}$, GE Rose ${ }^{2,4}$ and SP Newman ${ }^{1}$

\begin{abstract}
Purpose Graves' orbitopathy (GO) is associated with changes in the appearance of the eyes and visual dysfunction. Patients report feeling socially isolated and unable to continue with day-to-day activities. This study aimed at investigating the demographic, clinical, and psychosocial factors associated with quality of life in patients presenting for orbital decompression surgery.

Methods One-hundred and twenty-three adults with GO due for orbital

decompression at Moorfields Eye Hospital London were recruited prospectively. Clinical measures including treatment history, exophthalmos, optic neuropathy, and diplopia were taken by an ophthalmologist.

Participants completed psychosocial questionnaires, including the Graves' Ophthalmopathy Quality of Life Scale (GO-QOL), the Hospital Anxiety and Depression Scale, and the Derriford Appearance Scale. Hierarchical multiple regression analyses were used to identify predictors of quality of life.

Results Higher levels of potential cases of clinical anxiety $(37 \%)$ and depression (26\%) were found in this study sample than in patients with other chronic diseases or facial disfigurements. A total of $55 \%$ of the variance in GO-QOL visual function scores was explained by the regression model; age, asymmetrical GO and depressed mood were significant unique contributors. In all, $75 \%$ of the variance in GO-QOL appearance scores was explained by the regression model; gender, appearance-related cognitions and depressed mood were significant unique contributors.
\end{abstract}

Conclusion Appearance-related quality of life and mood were particularly affected in this sample. Predominantly psychosocial characteristics were associated with quality of life. It is important when planning surgery for patients that clinicians be aware of factors that could potentially influence outcomes. Eye (2015) 29, 951-957; doi:10.1038/eye.2015.76; published online 22 May 2015

\section{Introduction}

Graves' orbitopathy (GO) is an autoimmune thyroid disorder that affects the eyes. An estimated $25-50 \%$ of patients with Graves' disease develop GO. ${ }^{1}$ The most common early symptom of GO is a noticeable change in the appearance of the eyes, including redness of the eyelids, swelling, and disfiguring proptosis. ${ }^{2}$

Patients with GO report feeling stared at by others and socially isolated as a consequence of their changed appearance ${ }^{3}$ and this has a significant impact on mood. ${ }^{4}$ There is also growing evidence that GO has a detrimental impact on vision-related daily functioning including reading, watching TV, and driving. ${ }^{5-7}$ People with GO have been found to have a poorer quality of life than patients with other chronic conditions including diabetes, emphysema, and heart failure. ${ }^{4,8}$ Although it is important to establish the impact GO may have on a patient's well-being, it is equally important to understand what factors explain how some people live within normal levels of mood and experience a better quality of life than others.

There is mixed evidence to support an association between clinical factors and quality of life in GO. For instance, although Park $e t \mathrm{al}^{7}$ found that poorer quality of life was associated
${ }^{1}$ Centre for Health Services Research, School of Community \& Health Sciences, City University London, London, UK

${ }^{2}$ Adnexal Department Moorfields Eye Hospital, London, UK

${ }^{3}$ Community Health Newham, East London Foundation Trust, London, UK

${ }^{4} \mathrm{UCL}$ Institute of Ophthalmology, NIHR Biomedical Research Centre for Ophthalmology, London, UK

Correspondence: SP Newman, School of Community \& Health Sciences, City University London, 10 Northampton Square, London EC1V OHB, UK

Tel: +44 (0)20 7040 5755; Fax: +44 (0)20 70405717. E-mail: Stanton.newman.1 @city.ac.uk

Received: 18 February 2015 Accepted in revised form: 28 March 2015 Published online: 22 May 2015 
with more severe disease, including diplopia and dry eyes, Kulig et $a l^{9}$ failed to replicate these findings either before or after treatment for GO. Recent literature about appearance and disfigurement has suggested significant variability amongst individuals with disfiguring conditions-with many adjusting positively to living with a visible difference-and that psychological processes rather than objective measurements can better explain this variability in adjustment. ${ }^{10,11}$ In GO, Kahaly et $a l^{4}$ found that depressive coping, trivialising the condition, and higher levels of emotional distress were associated with poorer physical and mental quality of life. However, other psychosocial variables, identified within a framework for adjustment to disfigurement as proposed by The Appearance Research Collaboration, ${ }^{11}$ have not been investigated within the GO population. The framework suggests that a number of intervening cognitive processes, individual to each patient, might help explain the quality of life in people with a disfiguring condition.

It was hypothesised that there will be large variation in quality of life between individuals with GO, and that intervening psychosocial processes would better explain this variation than demographic or clinical factors.

\section{Materials and methods}

\section{Participants}

Patients were recruited from Moorfields Eye Hospital, London. Eligible patients aged 18 years or more with a consultant-led diagnosis of GO, and having been listed for orbital decompression surgery, were invited to participate in the study by a researcher (SW). Patients were excluded if they were considered by the consultant ophthalmologist to have inadequate comprehension of written and spoken English, or were suffering from psychiatric or co-morbid health conditions that rendered them too ill or distressed to take part.

\section{Study design}

A prospective cross-sectional design was used.

\section{Measures}

Demographics Self-reported age, gender, marital status, and ethnicity were collected.

Clinical measures The clinical measures assessed when patients were listed for surgery included ophthalmic disease duration, thyroid function, treatment history, laterality of GO and planned surgery, smoking status, upper and lower margin-reflex distance (MRD1 and MRD2; $\mathrm{mm}$ ), and the presence of corneal superficial punctate keratopathy, diplopia, and/or signs of hydraulic orbital disease. Disease activity was measured using the Clinical Activity Scale, ${ }^{12}$ a 10-item measure covering four of the five classic signs of inflammation (pain, redness, swelling, and impaired ocular function). Visual acuity was measured for each eye using a Snellen Chart. This was converted to the log of the minimal angle of resolution, ranging between -0.20 and 2.1, with a score of 2.2 assigned to patients with vision of counting fingers or worse. Optic neuropathy was identified using Ishihara colour testing and the presence of a relative afferent pupillary defect. Proptosis was measured using an Oculus exophthalmometer (in $\mathrm{mm}$ ), and the degree of asymmetry gauged from the difference between each eye (in $\mathrm{mm}$ ).

Psychosocial measures Self-report questionnaires were completed by participants at the time they were listed for surgery. The questionnaires chosen for this study were based on a proposed framework of adjustment to GO developed by the research team (Figure 1) adapted from The Appearance Research Collaboration's framework. ${ }^{11}$ Existing validated measures were used where possible, and brief versions of questionnaires were adopted to reduce participant burden.

Primary outcome measure Quality of life was measured using the Australian version of Graves' Ophthalmopathy Quality of Life Questionnaire (GO-QOL). ${ }^{7}$ The GO-QOL is made up of two subscales: 'vision-related' and 'appearance-related' quality of life. ${ }^{5}$ The GO-QOL has been found to be a valid and reliable disease-specific measure of quality of life with high internal consistency ( $\alpha=0.86$ for the visual function scale and $\alpha=0.82$ for the appearance scale). ${ }^{13}$ Subscale scores were calculated by following the questionnaire guidelines, ${ }^{13}$ and higher scores on each subscale indicate better health-related quality of life.

Socio-cognitive factors The Brief Fear of Negative Evaluation scale ${ }^{14}$ was used to measure anxiety about others' opinions. This 12-item brief version correlates highly with the original scale $(\alpha=0.96)$, and higher scores indicate a greater fear of negative evaluation from others.

The Iowa-Netherlands Comparison Orientation Measure ${ }^{15}$ measures how well respondents feel they are doing in life when comparing him or herself with others. This 11-item scale has been demonstrated to have good internal consistency $(\alpha=0.83)$, and higher scores indicate a greater tendency to make social comparisons.

The Multidimensional Scale of Perceived Social Support $^{16}$ measures subjective levels of social support from family, friends, and significant others. The overall scale has demonstrated good internal consistency $(\alpha=0.88)$ and test-retest reliability $(r=0.85)$. 


\begin{tabular}{|c|c|c|c|c|c|c|}
\hline \multicolumn{2}{|c|}{ PREDISPOSING FACTORS } & \multicolumn{4}{|c|}{ INTERVENING PSYCHOLOGICAL PROCESSES } & \multirow{2}{*}{$\begin{array}{l}\text { OUTCOMES } \\
\text { Quality of Life }\end{array}$} \\
\hline $\begin{array}{l}\text { Demographic } \\
\text { (BLOCK 1) }\end{array}$ & $\begin{array}{c}\text { Clinical } \\
\text { (BLOCK 2) }\end{array}$ & $\begin{array}{l}\text { Socio-cognitive } \\
\text { Factors } \\
\text { (BLOCK 3) }\end{array}$ & $\begin{array}{l}\text { Expectations } \\
\text { (BLOCK 4) }\end{array}$ & $\begin{array}{c}\text { Appearance-specific } \\
\text { Cognitions } \\
\text { (BLOCK 5) }\end{array}$ & $\begin{array}{c}\text { Mood } \\
\text { (BLOCK 6) }\end{array}$ & \\
\hline $\begin{array}{l}\text { Age } \\
\text { Gender } \\
\text { Ethnicity } \\
\text { Relationship } \\
\text { status }\end{array}$ & $\begin{array}{l}\text { Disease duration } \\
\text { Smoking } \\
\text { Previous treatments } \\
\text { Thyroid function } \\
\text { Laterality of GO } \\
\text { Laterality of surgery } \\
\text { Optic neuropathy } \\
\text { LogMAR } \\
\text { Exophthalmos } \\
\text { Asymmetry } \\
\text { Corneal SPKS } \\
\text { Hydraulic orbit } \\
\text { MRD1 } \\
\text { MRD2 } \\
\text { Diplopia } \\
\text { CAS score }\end{array}$ & $\begin{array}{l}\text { Fear of negative } \\
\text { evaluation (BFNE) } \\
\text { Social comparisons } \\
\text { (INCOM) } \\
\text { Perceptions of } \\
\text { social support } \\
\text { (MSPSS) }\end{array}$ & $\begin{array}{l}\text { Expectations for } \\
\text { appearance } \\
\text { concern (E-TEDS) } \\
\text { Expectations for } \\
\text { visual function (E- } \\
\text { TEDS) } \\
\text { Expectations for } \\
\text { intimacy and } \\
\text { social relationships } \\
\text { (E-TEDS) }\end{array}$ & $\begin{array}{l}\text { Appearance-related } \\
\text { social anxiety \& } \\
\text { avoidance (DAS24) } \\
\text { Evaluation of own } \\
\text { appearance } \\
\text { (CARVAL) } \\
\text { Salience of appearance } \\
\text { (CARSAL) } \\
\text { Perceived visibility }\end{array}$ & $\begin{array}{l}\text { Anxiety (HADS) } \\
\text { Depression (HADS) }\end{array}$ & $\begin{array}{l}\text { Visual function } \\
\text { (GO-QOL) } \\
\text { Appearance (GO- } \\
\text { QOL) }\end{array}$ \\
\hline
\end{tabular}

Figure 1 The potential variables to be used in hierarchical multiple regressions to explore factors associated with quality-of-life scores. The framework is adapted from The Appearance Research Collaboration. ${ }^{11}$

Higher scores on each 4-item subscale indicate greater perceived social support.

Patient expectations of treatment Expectations of GO surgery: In the absence of a GO-specific measure of a patients' expectations of treatment, an existing questionnaire- the Expectations of Strabismus Surgery Questionnaire ${ }^{17}$ —was adapted with the items being reviewed for relevance to GO. The 23-item questionnaire assessed patients' expectations in relation to three domains: 'appearance concerns', 'visual functioning', and 'intimacy and social relationships'. Participants were instructed to rate how they expected surgery to change these aspects of their lives, for instance 'my vision' on a Likert scale from 1 ('Made considerably worse') to 5 ('Considerably improve'). Higher scores indicate a greater expectation for these areas to improve after surgery.

Appearance-specific cognitions The Derriford Appearance Scale ${ }^{18}$ measures the impact of appearance-related distress including social anxiety and avoidance. This measure has demonstrated high internal consistency $(\alpha=0.92)$ and good test-retest reliability $(r=0.82)$, and higher scores represent greater levels of appearancerelated distress and social avoidance.

The Valence and Salience of Appearance scales (CARVAL \& CARSAL) ${ }^{19}$ measure how an individual evaluates his or her own physical appearance (CARVAL) and the extent to which physical appearance is important to the individual (CARSAL). Higher scores on each brief measure indicate a more negative self-evaluation of appearance and that greater value is placed on appearance, respectively. Both questionnaires have demonstrated high internal consistency (Pearson's $r$ correlations between 0.72 and 0.84 ).
Perceived Visibility of GO: patients were asked to rate how visible they felt their proptosis was to other people on a 7-point Likert scale from 1 ('Not at all visible') to 7 ('Extremely visible').

Mood The Hospital Anxiety \& Depression scale $(\text { HADS })^{20}$ has been designed to screen for depression and anxiety in patients with health problems. Higher total subscale scores on this valid and reliable measure indicate greater levels of anxious or depressed mood. Cut-off scores were also applied to identify non-cases (0-7), doubtful cases (8-10), and cases of possible clinical anxiety or depression (scores of 11 and over).

\section{Statistical analysis}

Using G*Power (version 3.1.7, Franz Faul, Universitat Kiel, Kiel, Germany), it was estimated that between 64 and 97 patients would be needed to achieve a power of $90 \%$ with effect sizes of 0.45 and 0.9 for the GO-QOL appearance and GO-QOL visual function subscales, respectively. ${ }^{13}$

All other statistical analyses were performed using IBM SPSS 21 (IBM UK Ltd, Portsmouth, UK). Levels of missing data, analysed using Little's Missing Completely at Random test, were shown to be Missing Completely at Random $\left(\chi^{2}=7127, \mathrm{df}=8177, P=1.000\right)$, with $11.9 \%$ of the data missing at item level. Multiple imputation was undertaken, and 10 imputed data sets were generated. Scale scores for the psychosocial variables were recalculated and the analysis was conducted on all 10 data sets and the results were pooled.

Univariate linear regressions were performed to explore the relationship between each of the independent variables and the GO-QOL subscale scores (dependent variables). Hierarchical multiple regressions were 
conducted using only the variables that were found to be significantly associated with each GO-QOL subscale. The hierarchy used to enter the predictors into the regression was based on the framework outlined in Figure 1.

Cohen's $f^{2}$ was used to calculate effect sizes for each of these regressions. ${ }^{21}$ The variables were also examined for multicollinearity, linearity, and homoscedasticity.

Multicollinearity was identified using VIF scores provided in SPSS after each regression analysis, with scores above 10 indicating multicollinearity. ${ }^{22}$ Histograms and normal probability plots were assessed for linearity and homoscedasticity.

\section{Statement of ethics}

Ethical approval was obtained from the North London Research Ethics Committee (reference 11/H0724/6). We certify that all applicable institutional and governmental regulations concerning the ethical use of human volunteers were followed during this research.

\section{Results}

Among 192 patients identified as eligible for the study, $135(70 \%)$ agreed to take part, and 123 of the 135 enrolled (91\%) returned their questionnaire. Two participants' data were removed from analysis because of high proportions of missing data (>50\%).

The descriptive characteristics of the study population are shown in Table 1.

Summary statistics for the psychosocial variables are shown in Table 2. Possible cases of clinical depression were detected in $26 \%$ of patients, and $37 \%$ had possible clinical levels of anxiety; 25 (21\%) participants experienced both. The large standard deviations for both GO-QOL subscales indicate great variability in adjustment from patient to patient.

Ten of the original 36 variables were significantly associated with the GO-QOL visual function subscale using univariate analyses: age $\left(\mathrm{F}_{1,119}=16.6, P<0.001\right.$, $\left.f^{2}=0.14\right)$, optic neuropathy $\left(\mathrm{F}_{1,119}=15.8, P<0.001\right.$, $\left.f^{2}=0.15\right), \log$ of the minimal angle of resolution $\left(\mathrm{F}_{1,119}=15.6, P<0.001, f^{2}=0.12\right)$, previous immunosuppression $\left(\mathrm{F}_{1,119}=11.1, P=0.001, f^{2}=0.09\right)$, asymmetrical GO $\left(\mathrm{F}_{1,119}=6.12, P=0.015, f=0.05\right)$, hydraulic orbit $\left(\mathrm{F}_{1,119}=9.22, P=0.003, f^{2}=0.06\right)$, diplopia $\left(\mathrm{F}_{1,119}=7.77, P=0.006, f=0.07\right)$, Clinical Activity Scale $\left(\mathrm{F}_{1,119}=6.22, P=0.014, f^{2}=0.05\right)$, appearance-related social anxiety and avoidance $\left(\mathrm{F}_{1,119}=3.95, P=0.049\right.$, $\left.f^{2}=0.06\right)$, anxiety $\left(\mathrm{F}_{1,119}=12.9, P<0.001, f^{2}=0.11\right)$, and depression $\left(\mathrm{F}_{1,119}=41.6, P<0.001, f^{2}=0.36\right)$.

After entry of these variables into the model in the order shown in Figure 1,55\% of the observed sample variation in GO-QOL visual function score was accounted
Table 1 Demographic and clinical characteristics of the study sample

\begin{tabular}{|c|c|c|c|}
\hline Variable & $\mathrm{n}(\%)$ & Range & Mean $\pm S D$ \\
\hline Age (years) & & $22-79$ & $47.1 \pm 12.3$ \\
\hline \multicolumn{4}{|l|}{ Gender } \\
\hline Male & $33(27)$ & & \\
\hline Female & $88(73)$ & & \\
\hline \multicolumn{4}{|l|}{ Ethnicity } \\
\hline Asian & $11(9.1)$ & & \\
\hline White British/Irish/other & $95(78)$ & & \\
\hline Black African/Caribbean/other & $15(12)$ & & \\
\hline \multicolumn{4}{|l|}{ Relationship status } \\
\hline Married/living with partner & $73(60)$ & & \\
\hline Single/other & $48(40)$ & & \\
\hline Disease duration (months) & & $4-336$ & $62.01 \pm 42$ \\
\hline \multicolumn{4}{|l|}{ Laterality of GO } \\
\hline Bilateral & $101(83)$ & & \\
\hline Unilateral & $20(17)$ & & \\
\hline \multicolumn{4}{|l|}{ Laterality of planned surgery } \\
\hline Bilateral & $79(65)$ & & \\
\hline Unilateral & $42(35)$ & & \\
\hline \multicolumn{4}{|l|}{ Treatment history } \\
\hline Previous immunosuppressants & $58(48)$ & & \\
\hline Previous radiotherapy & $18(15)$ & & \\
\hline Previous eyelid or orbital surgery & $14(12)$ & & \\
\hline \multicolumn{4}{|l|}{ Thyroid function } \\
\hline Stable & $106(88)$ & & \\
\hline Unstable & $15(12)$ & & \\
\hline Visual acuity (LogMAR conversion) ${ }^{a}$ & & $0-2$ & $0.1 \pm 0.4$ \\
\hline Superficial punctate keratopathy & $39(32)$ & & \\
\hline Hydraulic orbital signs & $25(21)$ & & \\
\hline Optic neuropathy & $15(12)$ & & \\
\hline Diplopia & $62(51)$ & & \\
\hline Marginal reflex distance $1(\mathrm{~mm})^{\mathrm{a}}$ & & $1.5-13$ & $5.9 \pm 2.1$ \\
\hline Marginal reflex distance $2(\mathrm{~mm})^{\mathrm{a}}$ & & $4-11$ & $6.7 \pm 1.4$ \\
\hline Exophthalmometry $(\mathrm{mm})^{\mathrm{a}}$ & & $15-33$ & $23.7 \pm 2.7$ \\
\hline Asymmetry (mm) & & $0-8$ & $1.8 \pm 1.8$ \\
\hline Clinical activity score & & $0-9$ & $1.12 \pm 1.9$ \\
\hline Smokers & $38(31)$ & & \\
\hline
\end{tabular}

${ }^{\mathrm{a}} \mathrm{A}$ worst eye analysis was conducted on these variables, based on the amount of proptosis.

for $\left(R^{2}=0.55, \mathrm{~F}_{1,119}=9.89, P<0.001, f^{2}=0.8\right)$. Betacoefficients indicated that age, asymmetrical GO, and depression made significant unique contributions to the model, above other factors (Table 3 ).

Univariate analyses indicated that $13 / 36$ variables were significantly associated with GO-QOL appearance: age $\left(\mathrm{F}_{1,119}=5.42, P=0.022, f^{2}=0.05\right)$, gender $\left(\mathrm{F}_{1,119}=8.13\right.$, $P=0.005, f=0.07)$, previous surgery $\left(\mathrm{F}_{1,119}=5.55\right.$, $P=0.020, f=0.06)$, family support $\left(\mathrm{F}_{1,119}=5.12, P=0.025\right.$, $\left.f^{2}=0.04\right)$, friends support $\left(\mathrm{F}_{1,119}=7.39, P=0.008, f=0.06\right)$, fear of negative evaluation $\left(\mathrm{F}_{1,119}=58.8, P<0.001, f^{2}=0.52\right)$, 
Table 2 Scores for the psychosocial measures at baseline for the study sample

\begin{tabular}{|c|c|c|c|c|c|}
\hline Variable & Min & $\operatorname{Max}$ & Max possible & Mean & $S D$ \\
\hline GO-QOL appearance score & 0 & 93.8 & 100 & 36.3 & 24.1 \\
\hline GOQOL visual function score & 2.8 & 100 & 100 & 64.0 & 26.7 \\
\hline BFNE & 14 & 60 & 60 & 38 & 9.2 \\
\hline INCOM & 16 & 54 & 55 & 36 & 7.2 \\
\hline MSPSS family & 4 & 20 & 20 & 15.3 & 4.5 \\
\hline MSPSS friends & 4 & 20 & 20 & 15.2 & 4.2 \\
\hline MSPSS significant other & 4 & 20 & 20 & 15.6 & 5.2 \\
\hline CARSAL & 5 & 30 & 30 & 25.2 & 4.7 \\
\hline CARVAL & 11 & 48 & 48 & 38.7 & 8.4 \\
\hline DAS24 & 22 & 83 & 96 & 51.3 & 13 \\
\hline Men $(n=33)$ & 22 & 83 & 96 & 50.7 & 15 \\
\hline Women $(n=88)$ & 22 & 83 & 96 & 51.6 & 12 \\
\hline Visibility & 1 & 7 & 7 & 5.7 & 1.5 \\
\hline HADS depression & 1 & 21 & 21 & 9.2 & 4.9 \\
\hline HADS anxiety & 0 & 19 & 21 & 7.6 & 4.7 \\
\hline
\end{tabular}

Table 3 The final step of a hierarchical multiple regression model, with GO-QOL visual function score as the dependent variable

\begin{tabular}{lrrrl}
\hline & $\mathrm{B}$ & $S E \mathrm{~B}$ & $\mathrm{t}$ & $\mathrm{p}$ \\
\hline (Constant) & 119.49 & 13.78 & 8.67 & $0.000^{* *}$ \\
Age & -0.50 & 0.19 & -2.63 & $0.009^{*}$ \\
LogMAR & -11.28 & 6.45 & -1.75 & 0.080 \\
CAS & -1.92 & 1.31 & -1.46 & 0.144 \\
Asymmetry & -2.25 & 1.13 & -2.00 & $0.046^{*}$ \\
Optic neuropathy & -4.09 & 9.54 & -0.43 & 0.669 \\
Hydraulic orbit & 2.55 & 6.47 & 0.39 & 0.694 \\
Previous immunomodulation & -6.79 & 4.90 & -1.38 & 0.168 \\
Diplopia & -4.39 & 4.29 & -1.02 & 0.307 \\
DAS24 & 0.05 & 0.21 & 0.23 & 0.815 \\
HADS anxiety & -0.69 & 0.58 & -1.20 & 0.231 \\
HADS depression & -2.41 & 0.59 & -4.10 & $0.000^{* *}$ \\
\hline
\end{tabular}

${ }^{*} P<0.05,{ }^{* *} P<0.001$.

social comparison $\left(\mathrm{F}_{1,119}=12.2, P=0.001, f^{2}=0.11\right)$, appearance-related social anxiety and avoidance $\left(\mathrm{F}_{1,119}=60.0, P<0.001, f=0.59\right)$, salience of appearance $\left(\mathrm{F}_{1,119}=64.6, P<0.001, f=0.51\right)$, valence of appearance $\left(\mathrm{F}_{1,119}=98.9, P<0.001, f=0.76\right)$, perceived visibility $\left(\mathrm{F}_{1,119}=27.5, P<0.001, f^{2}=0.24\right)$, anxiety $\left(\mathrm{F}_{1,119}=42.2\right.$, $\left.P<0.001, f^{2}=0.39\right)$, and depression $\left(\mathrm{F}_{1,119}=70.5, P<0.001\right.$, $\left.f^{2}=0.57\right)$.

After entry of the variables using the same model as before, $75 \%$ of the observed sample variation in GOQOL appearance scores was accounted for $\left(R^{2}=0.75\right.$, $\left.\mathrm{F}_{13,107}=20.7, P<0.001, f^{2}=2.3\right)$. Beta-coefficients indicated that gender, appearance-related social anxiety and social avoidance, salience of appearance, valence of appearance, perceived visibility of GO, and
Table 4 The final step of a hierarchical multiple regression model, with GO-QOL appearance-related score as the dependent variable

\begin{tabular}{lrrrl}
\hline & \multicolumn{1}{c}{$B$} & SE B & \multicolumn{1}{c}{$\mathrm{t}$} & P-value \\
\hline (Constant) & 132.09 & 13.84 & 9.55 & $0.000^{* *}$ \\
Age & 0.11 & 0.11 & 0.94 & 0.346 \\
Gender & 6.56 & 3.02 & 2.17 & $0.03^{*}$ \\
Previous surgery & -5.04 & 5.08 & -0.99 & 0.325 \\
BFNE & -0.23 & 0.22 & -1.03 & 0.302 \\
INCOM & 0.01 & 0.23 & 0.06 & 0.950 \\
MSPSS family & -0.29 & 0.34 & -0.87 & 0.382 \\
MSPSS friends & 0.56 & 0.37 & 1.53 & 0.127 \\
DAS24 & -0.39 & 0.13 & -2.93 & $0.004^{*}$ \\
CARSAL & -1.23 & 0.33 & -3.69 & $0.000^{* *}$ \\
CARVAL & -0.58 & 0.21 & -2.76 & $0.006^{*}$ \\
Perceived visibility & -2.75 & 0.96 & -2.86 & $0.004^{*}$ \\
HADS anxiety & -0.05 & 0.39 & -0.14 & 0.891 \\
HADS depression & -1.12 & 0.43 & -2.60 & $0.009^{*}$ \\
\hline${ }^{*} P<0.05,{ }^{* *}>0.001$. & & & &
\end{tabular}

depression all made significant contributions to the model (Table 4).

\section{Discussion}

This study investigated the factors that may be associated with quality of life in patients with GO presenting for orbital decompression surgery. It was found that being older, having asymmetrical proptosis, and having higher levels of depressed mood were associated with poorer vision-related quality of life. Similarly, a greater value being placed on appearance, a more negative evaluation of appearance, greater perceived visibility of GO, and having higher levels of depressed mood were all associated with poorer appearance-related quality of life.

Participants in this study experienced levels of anxiety and depression greater than the general population ${ }^{23}$ and those living with other visibly disfiguring conditions. ${ }^{24}$ GO-QOL visual function scores were comparable to normative values established in a previous GO sample, ${ }^{13}$ but GO-QOL appearance scores were considerably lower. These results suggest that, for many, the changed appearance caused by GO has a greater impact and is more debilitating than previously reported in the literature.

Appearance-related quality of life was significantly associated with gender. For women, the eyes might be regarded as central in perceived attractiveness, and changes in ocular appearance could have a detrimental influence on self-confidence and willingness to appear in photographs. Recent studies have suggested that women with visible differences, including strabismus, may experience higher levels of appearance-related distress than men, ${ }^{25,26}$ which in turn could have an impact on 
their quality of life in this domain. Furthermore, age was found to be associated with vision-related quality of life, which might reflect the greater disease severity often found in older age.

Appearance-related cognitions were particularly important in predicting appearance-related quality of life. Increased social anxiety was associated with both poorer vision-related and appearance-related quality of life in this study, analogous to strabismus. ${ }^{27}$ Increased importance of appearance-related information, as well as having a poorer evaluation of one's own appearance, were also associated with quality of life in this sample. Terwee $e a^{28}$ found in a study investigating perceptions of the severity of GO in different groups of observers and patients themselves that clinicians tended to under-rate, and patients over-rate, the severity of GO: This emphasises the importance of eliciting a patient's perspective during pre-surgical assessment to improve the chance of generating realistic patient expectations about what surgery can achieve.

A limitation of the study is the cross-sectional design, which does not enable causal direction to be established and longitudinal studies that follow patients over time are needed. If patients in this study were not euthyroid, present hyper- or hypothyroidism could have affected their quality of life. However, recent research found no difference in the quality of life of people with thyroid dysfunction compared with people with normal thyroid levels, ${ }^{29}$ and it is possible that this may not have biased the results of this study. It is also possible that quality of life may predict mood in GO. However, mood has been found to be a strong predictor of quality of life in strabismus, ${ }^{24}$ supporting the current findings.

Furthermore, by exploring other factors that might explain variance in quality of life in this population, rather than examining quality of life and mood in isolation, this study has expanded on previous studies and has provided a new insight into the experiences of patients with GO.

In conclusion, there was significant variation in quality of life in this sample, suggesting that some people adjust successfully to living with GO, but for others the impact is extreme. Contrary to conventional medical perspectives, this variation was predominantly accounted for by intervening cognitive processes, rather than objective measures. There was, however, evidence that older age and asymmetrical disease were associated with poorer vision-related quality of life. The high proportion of patients with potentially diagnosable clinical depression and anxiety should be of concern to clinicians, and it highlights the need for additional psychosocial support.

\section{Summary}

\section{What was known before}

- Quality of life in Graves' orbitopathy is reduced owing to changes in appearance and visual dysfunction. In other disfiguring conditions, a variety of psychological processes have explained variation in quality of life.

\section{What this study adds}

- Identification of psychological factors that are associated with quality of life over and above clinical factors in Graves' orbitopathy. The severity of the impact of Graves' orbitopathy on mood.

\section{Conflict of interest}

The authors declare no conflict of interest.

\section{Acknowledgements}

The authors acknowledge those who funded the research (City University London and Moorfields Eye Hospital Special Trustees). The authors also thank colleagues at Moorfields Eye Hospital who assisted with recruitment and data collection for the study. DGE and GER received partial funding from the Department of Health's NIHR Biomedical Research Centre for Ophthalmology at Moorfields Eye Hospital and UCL Institute of Ophthalmology. The views expressed in this publication are those of the authors and not necessarily those of the Department of Health.

\section{References}

1 Bahn RS, Heufelder AE. Pathogenesis of Graves' ophthalmopathy. N Engl J Med 1993; 329: 1468-1475.

2 Dickinson AJ. Clinical manifestations. In: Wiersinga WM, Kahaly GJ (eds). Graves' Orbitopathy: A Multidisciplinary Approach - Questions and Answers. Karger: Basel, Switzerland, 2010 pp 1-25.

3 Jensen AL, Harder I. The impact of bodily change on social behaviour in patients with Thyroid-Associated Ophthalmopathy. Scand J Caring Sci 2011; 25(2): 341-349.

4 Kahaly GJ, Hardt J, Petrak F, Egle UT. Psychosocial factors in subjects with thyroid-associated ophthalmopathy. Thyroid 2002; 12(3): 237-239.

5 Choi YJ, Lim HT, Lee SJ, Lee SY, Yoon JS. Assessing Graves' ophthalmopathy-specific quality of life in Korean patients. Eye 2012; 26(4): 544-551.

6 Ponto KA, Hommel G, Pitz S, Elflein H, Pfeiffer N, Kahaly GJ. Quality of life in a German Graves orbitopathy population. Am J Ophthalmol 2011; 152(3): 483-490.

7 Park JJ, Sullivan TJ, Mortimer RH, Wagenaar M, Perry-Keene DA. Assessing quality of life in Australian patients with Graves' ophthalmopathy. Br J Ophthalmol 2004; 88: 75-78.

8 Gerding MN, Terwee CB, Dekker FW, Koornneef L, Prummel MF, Wiersinga WM. Quality of life in patients with Graves' ophthalmopathy is markedly decreased: 
measurement by the medical outcomes study instrument. Thyroid 1997; 7(6): 885-889.

9 Kulig G, Andrysiak-Mamos E, Sowinska-Przepiera E, Kulig J, Karakiewicz B, Brodowski J et al. Quality of life assessment in patients with Graves' disease and progressive infiltrative ophthalmopathy during combined treatment with methylprednisolone and orbital radiotherapy.

Endokrynol Pol 2009; 60(3): 158-165.

10 Rumsey N, Clarke A, White P, Wyn-Williams M, Garlick W. Altered body image: appearance-related concerns of people with visible disfigurement. J Adv Nurs 2004; 48(5): 443-453.

11 Clarke A, Thompson AR, Jenkinson E, Rumsey N, Newell R. CBT for Appearance Anxiety. John Wiley \& Sons: Chichester, UK, 2014.

12 Mourits MP, Prummel MF, Wiersinga WM, Koornneef L. Clinical activity score as a guide in the management of patients with Graves' ophthalmopathy. Clin Endocrinol 1997; 47: 9-14.

13 Terwee CB, Dekker FW, Mourits MP, Gerding MN, Baldeschi L, Kalmann R et al. Interpretation and validity of changes in scores on the Graves' ophthalmopathy quality of life questionnaire (GO-QOL) after different treatments. Clin Endocrinol (Oxf) 2001; 54(3): 391-398.

14 Leary MR. A brief version of the Fear of Negative Evaluation Scale. Personal Soc Psychol Bull 1983; 9(3): 371-375.

15 Gibbons FX, Buunk BP. Individual differences in social comparison: development of a scale of social comparison orientation. J Pers Soc Psychol 1999; 76(1): 129-142.

16 Zimet GD, Dahlem NW, Zimet SG, Farley GK. The multidimensional scale of perceived social support. J Personal Assess 1988; 52(1): 30-41.

17 McBain HB, MacKenzie KA, Hancox J, Ezra DG, Adams GGW, Newman SP. Why do patients with strabismus choose to undergo realignment surgery and what are their expectations of post-surgical outcomes? Development of two questionnaires. Br J Ophthal (under review).

18 Carr T, Moss TP, Harris DL. The DAS24: a short form of the Derriford Appearance Scale DAS59 to measure individual responses to living with problems of appearance. $\mathrm{Br}$ J Health Psychol 2005; 10: 285-298.

19 Moss TP, Rosser BA. The moderated relationship of appearance valence on appearance self-consciousness: development and testing of new measures of appearance schema components. PLoS One 2012; 7(11): 1-7.

20 Zigmond AS, Snaith RP. The hospital anxiety and depression scale. Acta Psychiatr Scand 1983; 67: 361-370 1987.

21 Cohen J. A power primer. Psychol Bull 1992; 112(1): 155-159.

22 Field A. Discovering Statistics Using SPSS, 3rd edn. Sage: London, UK, 2009.

23 Crawford J, Henry J, Crombie C, Taylor EP. Brief report normative data for the HADS from a large non-clinical sample. Br J Clin Psychol 2001; 40(4): 429-434.

24 Martin CR, Newell RJ. Factor structure of the Hospital Anxiety and Depression Scale in individuals with facial disfigurement. Psychol Health Med 2004; 9(3): 327-336.

25 Rumsey N, Clarke A, White P. Exploring the psychosocial concerns of outpatients with disfiguring conditions. J Wound Care 2003; 12(7): 247-252.

26 James H, Jenkinson E, Harrad R, Ezra DG, Newman S. Appearance concerns in ophthalmic patients. Eye 2011; 25: 1039-1044.

27 McBain H, MacKenzie KA, Au C, Hancox J, Ezra DG, Adams GG et al. Factors associated with quality of life and mood in adults with strabismus. Br J Ophthalmol 2014; 98(4): 550-555.

28 Terwee CB, Dekker FW, Bonsel GJ, Heisterkamp SH, Prummel MF, Baldeschi $L$ et al. Facial disfigurement: Is it in the eye of the beholder? A study in patients with Graves' ophthalmopathy. Clin Endocrinol (Oxf) 2003; 58(2): 192-198.

29 Klaver EI, van Loon HCM, Stienstra R, Links TP, Keers JC, Kema IP et al. Thyroid hormone status and health-related quality of life in the lifelines cohort study. Thyroid 2013; 23(9): 1066-1073. 